\author{
ARTIGO \\ do/ https://doi.org/10.22481/rpe.v16i43.6871
}

\title{
EDUCAÇÃO, ESCRITA E TECNOLOGIAS: (REVERBER)AÇÕES DE PROFESSORES ALFABETIZADORES
}

\author{
EDUCATION, WRITING AND TECHNOLOGIES: (REVERBER)ACTIONS OF \\ LITERACY TEACHERS
}

\author{
EDUCACIÓN, ESCRITURA Y TECNOLOGÍAS: (REVERBER)ACCIONES DE LOS \\ PROFESORES DE ALFABETIZACIÓN
}

Adriana Cavalcanti dos Santos

Universidade Federal de Alagoas - Brasil

Nádson Araújo dos Santos

Universidade Federal de Alagoas - Brasil

Viviane Caline de Souza Pinheiro

Universidade Federal de Alagoas - Brasil

\begin{abstract}
Resumo: O artigo define por objetivo fomentar a discussão sobre as Tecnologias Digitais no processo de aquisição da língua escrita na escola. Apoiou-se nos pressupostos teóricos e epistemológicos de uma investigação qualitativa. Como suporte teórico dialogou com Bakhtin (2003); Pinto (2008); Soares (2003, 2016); Rojo (2013), entre outros. O texto focou na análise de um questionário elaborado e aplicado por meio da ferramenta Google Forms. Participaram da investigação voluntariamente 66 (sessenta e seis) professores alfabetizadores do ensino fundamental I. Os resultados obtidos apontaram que os professores apresentam dificuldades em conceituar o termo tecnologia digital e tendiam a considerá-lo como metodologia ou suporte tecnológico; as formações continuadas não atendem a todos os participantes; os professores externaram tentativas de inserirem as TD em seus planejamentos; e uma grande maioria, reconheceu que as TD contribuem significativamente para o processo de alfabetização.
\end{abstract}

Palavras chave: Tecnologias digitais. Professores alfabetizadores. Escrita.

\begin{abstract}
The objective of the article is to foment discussion on Digital Technologies in the process of acquiring written language at school. It was based on the theoretical and epistemological assumptions of a qualitative investigation. As a theoretical support, it dialogued with Bakhtin (2003); Pinto (2008); Soares (2003, 2016); Rojo (2013), among others. The text focused on the analysis of a questionnaire designed and applied using the tool Google Forms It has participated in the investigation voluntarily 66 (sixty-six) literacy teachers from elementary school.The results obtained showed that teachers have difficulties in conceptualizing the term digital technology and tended to consider it as a methodology or technological support; the continuing training doesn't serve all participants; the teachers expressed attempts to include DT in their planning; and a large majority recognized that DT contributes significantly to the literacy process.
\end{abstract}

Keywords:Digital technologies. Literacy teachers.Writing. 
Resumen: El objetivo del artículo es fomentar el debate sobre lastecnologíasdigitalesenelproceso de adquisicióndellenguaje escrito enlaescuela. Se basóenlossupuestos teóricos y epistemológicos de una investigacióncualitativa. Como soporte teórico, dialogócon Bakhtin (2003); Pinto (2008); Soares (2003, 2016); Rojo (2013), entre otros. El texto se centróenelanálisis de uncuestionariodiseñado y aplicado utilizando laherramientaFormularios de Google. Participaron voluntariamente enlainvestigación 66 (sesenta y seis) maestros de alfabetización de laescuela primaria. Los resultados obtenidosmostraron que los maestros tienendificultades para conceptualizar el término tecnología digital y tienden a considerarlo como una metodología o soporte tecnológico; lacapacitación continua no sirve a todos los participantes; los maestros expresaron intentos de incluir TD ensuplanificación; y una granmayoríareconoció que TD contribuye significativamente al proceso de alfabetización.

Palabras clave: Tecnologíasdigitales. Maestros de alfabetización. Escritura.

\section{Introdução}

Hodiernamente, com relação ao uso das Tecnologias Digitais (TD), consideradas novidades há alguns anos, sabe-se que atualmente incorporam-se ao cotidiano (CERTEAU, 2008), e passam a fazer parte das práticas comunicativas da sociedade letrada, a exemplo, os usos das redes sociais digitais. No entanto, pauta-se nos dias atuais, o desafio de utilizar as TD como recursos pedagógicos na sala de aula de modo a favorecer as aprendizagens de Língua Portuguesa dos alunos do ciclo de alfabetização ${ }^{1}$.

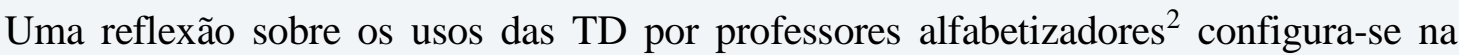
proposta deste trabalho, entendendo que as práticas de ensino mediadas pelos usos das TD podem ser uma estratégia metodológica favorável às aprendizagens da leitura e da escrita nos processos de alfabetização. Reconhecendo, assim, que os usos das TD permitem o contato dos alunos com os mais diversos gêneros do discurso (BAKHTIN, 2003) em suportes virtuais.

Ao problematizar os usos das TD no processo de alfabetização, este artigo apoia-se nos pressupostos epistemológicos de uma investigação qualitativa (TRIVIÑOS, 2013). Delineia-se por objetivo fomentar a discussão sobre as Tecnologias Digitais no processo de aquisição da língua escrita. Como aporte teórico fundamenta-se em Bakhtin (2003); Pinto (2008); Soares (2003, 2016); Rojo (2012, 2013); Santos (2014); Santos e Cavalcante (2019); Santos, Santos, Santos (2020); Pimentel e Costa (2017); Dudeney, Hockly e Pegrum (2016), entre outros.

\footnotetext{
${ }^{1}$ Segundo o documento norteador da Avaliação Nacional de Alfabetização (2013) o ciclo de alfabetização é composto pelos três primeiros anos do Ensino Fundamental, o qual terá até o $3^{\circ}$ ano para que os alunos sejam alfabetizados.

${ }^{2} \mathrm{O}$ uso do termo professor alfabetizador é usado, neste artigo, para identificar os professores do ciclo de alfabetização, segundo o PNE (2014), alunos do $1^{\circ}, 2^{\circ}$ e $3^{\circ}$ anos.
} 
O presente texto analisa os dados de um questionário produzido na ferramenta Google Formse enviado aos professores alfabetizadores, sujeitos da investigação. Ao ser finalizado, foi enviado por meio de endereço eletrônico para 300 (trezentos) e-mails de professores alfabetizadores atuantes em turmas do ciclo de alfabetização, funcionários públicos da Secretaria de Educação (SEMED) da cidade de Maceió-Alagoas. Estimou-se que cada respondente ocuparia, no máximo, dez minutos para responder todas as questões. As respostas aos questionários foram analisadas estatisticamente de forma anônima, preservando a identidade dos participantes. Ressaltamos que os dados foram coletados antes da pandemia do novo coronavírus (COVID-19), nos meses de janeiro e fevereiro de 2020 e, como veremos ao logo do texto, os resultados apontam para a realidade vivida em muitas das escolas em Alagoas.

O questionário on-lineusado como instrumento de coleta de dados, tinha o propósito de abordar o tratamento dado as TD em sala de aula nos processos de alfabetização, vislumbrando o foco nos usos e no conceito das TD, além de abordar à relação desses usos às aprendizagens LP. $\mathrm{O}$ referido instrumento de coleta de dados, estruturou-se em 7 (sete) questões. Destas, 5 (cinco) fechadas e 2 (duas) abertas. As questões abertas tinham por propósito garantir a coleta de marcas das singularidades dos alfabetizadores sobre o foco da investigação. Dos e-mails enviados, 300 (trezentos) endereços, 66 (sessenta e seis) professores os responderam, perfazendo um total de $22 \%$ de participação.

$\mathrm{O}$ artigo estrutura-se em quatro momentos. $\mathrm{O}$ primeiro discute as concepções do termo tecnologia e como se desenvolvem as TD na educação. O segundo enfatiza a relação entre os usos das TD e o professor alfabetizador, diante de uma perspectiva na qual se focaliza a formação continuada como eixo articulador, sobre o ensino de LP e o uso da TD. O terceiro aborda as TD e a sua contribuição/importância para o processo de alfabetização dos alunos. O quarto analisa o corpus da pesquisa. Em últimas palavras, são tecidas considerações finais.

\section{Tecnologias digitais e linguagem: ponderando aproximações}

Para começar o diálogo (BAKHTIN, 2003) é importante discutirmos o conceito polissêmico de TD em espaços e lugares praticados (CERTEAU, 2008). Para o autor, o espaço "é um lugar praticado", enquanto o lugar "é, portanto, uma configuração instantânea de posição" (2008, p. 201). Corroborando na discussão, Pinto (2008), alerta-nos para a impossibilidade de se entender o significado de TD se não há o afastamento do impressionismo e do sensacionalismo promotores da concepção de que as TD surgiram com o propósito de resolver todos os problemas da sociedade. 
O boom tecnológico, ocorrido ao longo do século XX, permite a reflexão sobre o conceito de tecnologia e suas relações na sociedade. $\mathrm{O}$ apogeu dos usos das TD estava destinado, entre outros aspectos, a desafiar os limites do conhecimento e a criar novos. Numa primeira aproximação, a tecnologia é entendida como produto de consumo, geradora de lucros numa sociedade capitalista. Todavia, as tecnologias sempre estiveram presentes no mundo, mas a visão sobre a necessidade de sua utilização vem mudando continuamente durante os séculos XX e XXI.

Embora, o conceito de tecnologia seja polissêmico (PINTO, 2008), pode-se entendê-la como as ferramentas tecnológicas criadas para suprir as necessidades humanas. Embora, o referido conceito pode ser entendido de forma mais abrangente. Segundo Pinto (2008), TD pode ser percebida: como o logos da técnica; como a própria técnica; como um conjunto de técnicas de uma sociedade no tempo; e, como ideologização da técnica.

Na primeira concepção, tecnologia como o logos da técnica, assume-se uma relação epistemológica com a técnica e de reflexão sobre ela. Compreende-se como um ato humano, ação mediada pelo homem (SILVA, 2013) em espaços e lugares praticados (CERTEAU, 2008). A concepção de tecnologia volta-se, então, para um processo reflexivo da construção de própria técnica. Na segunda concepção, como a própria técnica, existe o conflito de que a tecnologia acaba por ser confundida pela própria técnica (SILVA, 2013). Dessa maneira, percebe-se a técnica voltada para um sentido em si, sem evidenciar seu sentido reflexivo diante do conceito.

$\mathrm{Na}$ terceira concepção, como um conjunto de técnicas de uma sociedade no tempo, o entendimento sobre tecnologia associa-se ao conjunto de técnicas disponíveis a uma determinada sociedade e tempos históricos (PINTO, 2008). Portanto, as escolhas dessas técnicas envolvem a segregação de outros conjuntos de tecnologias que não são consideradas por grupos específicos de interesses. Na quarta concepção, como ideologização da técnica, transmite-se a ideia de que "supostamente, o ser humano, por meio da tecnologia, irá construir uma vida feliz para todos" (SILVA, 2013, p. 848). Nesse sentido, o homem passa a entender a tecnologia como parte necessária para o seu bem estar.

Ao se pensar a presença da tecnologia na sociedade, especificamente, na forma como ela a modifica e transforma as relações humanas por meio da linguagem, desde o início do surgimento da escola os artefatos tecnológicos fizeram parte dos seus cotidianos (CERTEAU, 2008). Assim, pródigos em inovações, os séculos XVIII e XIX, trouxeram para a escola primária, "a mesa de areia, a ardósia e o lápis de pedra, a pena metálica, o lápis de grafite, o papel e o caderno" (CHARTIER, 2000, p. 123), destacando-se ainda o uso do quadro negro para o professor escrever ou cadeiras para os alunos sentarem (VILELA, 2010). 
Nas escolas públicas brasileiras, no século XXI, a presença da TD tem por marco a criação do Programa Nacional de Tecnologia Educacional (ProInfo) (BRASIL, 2007), pelo Ministério da Educação (MEC). Esse programa tinha por objetivo investir em informática com uso pedagógico nas escolas públicas. A função do referido programa era equipar as escolas com computadores, recursos digitais e conteúdos educacionais. Aos municípios e aos estados federativos competiam reservar os locais adequados para a instalação dos equipamentos e capacitar/treinar os funcionários para o uso de tais recursos em contextos educacionais.

Com o ProInfo (BRASIL, 2007), questões que envolviam a formação dos professores para realizarem atividades em sala, com o uso dos recursos tecnológicos que objetivassem evidências pedagógicas para as aprendizagens dos alunos, emergiram na escola ou em atividades remotas. Sendo assim, mesmo com os incentivos propostos do ProInfo pelo MEC, observa-se há mais de 10 anos a precariedade da inserção e utilização das TD no espaço escolar. Essa precariedade vem tomando visibilidade, em "tempos de pandemia" da Covid-19 no Brasil e no Mundo, nos últimos meses. Em outras palavras, apesar do empenho das políticas governamentais, mesmo que escassas, observa-se que, em sentido metafórico, "ao subir, descer, girar ao redor das práticas, algumas coisas escap[ou] sem cessar, que não pod[ia] ser dita nem ensinada, mas dev[ia] ser praticada" (CHARTIER, 2000, p. 123), como chamava atenção Michel de Certeau (2008, p. 156), não provocando mudanças significativas nas metodologias de ensino.

As TD devem ser situadas no campo educacional como recurso pedagógico, tendo em vista que, "as tecnologias só são educacionais porque são utilizadas na escola como mediação da prática pedagógica, e porque servem a objetivos escolares constituindo-se parte integrante do programa curricular" (MARTINS; MASCHIO, 2014, p. 5). Corroborando na discussão, Santos e Cavalcante (2019, p. 81) defendem que para trabalhar com os recursos tecnológicos, os "professores, dessa era digital, necessitam focar nas mídias digitais, nas áreas de informática e na animação virtual". Esses autores postulam que, dessa forma, os professores podem se apropriar das TD, utilizando-as de forma pedagógica, nas reflexões sobre os usos das linguagens, com abordagens nos multiletramentos e nas multilinguagens (ROJO, 2012). Ribeiro (2016, p. 161) acrescenta que:

[...] o desenvolvimento de tecnologias de comunicação e de informação e sua crescente utilização no contexto social nos remete à necessidade premente de que a escola tem de estar atenta e aberta às mudanças que a inserção da sociedade no mundo digital exige para a socialização das novas gerações.

No processo de formação do aluno para os usos das TD,faz-se necessário lhe apresentar as mais diferentes formas de interações sociais por meio dos usos da língua, isto é, apresentar- 
lhe os mais diferentes gêneros discursivos (BAKHTIN, 2003) nas modalidades linguísticas oral e escrita, em suportes e contextos de ensino híbrido (BACICH; TANZI NETO; TREVISANI, 2015).

É possível entender que a relação entre as TD e o ensino da língua/linguagem no processo de alfabetização não se sobrepõem, mas os usos das TD contribuam efetivamente para aprendizagem da língua escrita na escola nos processos de alfabetização e de letramento digital (ZACHARIAS, 2016). Contudo, o computador não substitui o professor. A relação dele com a criança não beneficia a afetividade e a flexibilidade das interações humanas, das quais participa a relação mestre-aluno. Santos, Santos e Santos (2020, p. 04) ao discorrer sobre as TD e suas relações com aquisição da língua escrita, realçam que:

[...] a aprendizagem da língua escrita não acontece apenas na sala de aula, pois com as tecnologias digitais emergentes, novos espaços têm sido explorados e conquistados como lugar de produção e criação textual, mas é na escola que deve ocorrer uma organização dinâmica de objetivos práticos e autênticos favorecendo à construção do ser social leitor e produtor de gêneros discursivos diversos.

Os usos das TD na educação, especificamente no processo de alfabetização, permeiam o universo dinâmico dos discursos materializados em gêneros textuais em sala de aula e da relação pedagógica do professor e dos alunos com as TD em prol das aprendizagens, contribuindo assim, para as práticas de usos da linguagem no cotidiano escolar e para além dos seus muros. Com esse entendimento, é pertinente discutir o lugar do professor, como agente de inovação e mudança (HARGREAVES, 2001) no contexto de inserção das TD no contexto escolar.

\section{Professor alfabetizador e Tecnologias Digitais: uma possível aproximação}

A escola, por seu papel social, contribui para a disseminação dos "conhecimentos historicamente acumulados" pela humanidade nas mais diferentes áreas do conhecimento (MARTINS; MASCHIO, 2014, p. 06). Desse modo, atribui-se ao professor a função de disseminar os referidos conhecimentos em contextos de mudança e inovação pedagógica (SANTOS; LEITE; 2019). Segundo Fullan e Hargreaves (2001) não haverá mudança e inovação educativa sem a adesão dos professores. Esses autores afirmam também que os professores são os elementos-chave para a mudança educativa.

No que se refere ao desenvolvimento da competência linguística (COLOMER; CAMPS, 2002) dos alunos, têm-se o reconhecimento do uso das TD como recursos educacionais essenciais à aprendizagem. No desenvolvimento dessa competência, deve-se buscar promover maior 
compreensão dos conhecimentos digitais e um diálogo mais efetivo com os múltiplos letramentos na escola (ROJO, 2013).

As relações entre os usos das TD e o professor alfabetizador, no que diz respeito ao modo como mobilizam os saberes docentes (TARDIF, 2003) para mediar as práticas pedagógicas, enfatiza-se a necessidade de processos de formação continuada, além de considerar como os professores alfabetizadores são motivados e estão preparados para fazer uso desses recursos de forma que promovam efetivamente a aprendizagem dos alunos.

Em pesquisa realizada por Martins e Maschio (2014, p. 11), sobre uso do computador pelo professor, as autoras afirmam que "para os professores, a imagem construída sobre estas tecnologias foi revelada como importante ferramenta para a mudança de suas práticas e para o avanço da qualidade do processo ensino aprendizagem”. As mudanças na prática pedagógica do professor são percebidas diante da inserção de novos recursos e olhares para o processo de ensino e aprendizagem, assim como a sua vivência no âmbito profissional (NUNES, 2001).

A importância de evidenciar os saberes docentes dos professores alfabetizadores no contexto de formação continuada sobre os usos das TD, permite espaços de reflexões sobre a prática docente de modo que apontam para processos de ressignificação dos saberes construídos em suas histórias de vida e profissional (SANTOS, 2014). Em outras palavras, implica entender que "seus saberes vão-se constituindo a partir de uma reflexão na e sobre a prática" (NUNES, 2001, p. 30). Nessa perspectiva, as proposições da utilização das TD no ambiente escolar propõem continuamente desafios à prática docente.

O reconhecimento da valoração do professor alfabetizador em relação ao uso das TD e a forma como são integradas à sala de aula vão se colocando como aspectos essenciais na contemporaneidade. Assim, os saberes docentes (TARDIF, 2003) devem ser ampliados e ressignificados acerca das transformações sociais e das novas exigências à escola e aos professores. Isso implica em aprender a explorar recursos digitais em contexto de sala de aula com o intuito de favorecer mudanças educativas às aprendizagens. Entretanto, é necessário que o professor utilize e explore os recursos emergentes da cultura digital para que domine e reelabore o seu saber diante das transformações da sociedade (NUNES, 2001), ao passo que, a práxis, (FREIRE, 1987) seja (re)criada em meio aos diversos cenários educativos que se apresentem à escola.

No que se refere às TD e à prática docente, faz-se necessário que o professor, no uso de sua autonomia, posicione-se e defina quais recursos tecnológicos são mais propícios aos contextos e práticas específicas de alfabetização, aprendizagem da leitura e da escrita. Reverbera, 
portanto, nas pesquisas de Martins e Maschio (2014) e Cerny, Espíndola e Tosatti (2018) a ênfase da falta de habilidade dos professores em usarem as TD de forma autônoma. Dito isto, pensar a “intimidade" dos professores com os recursos digitais ainda é um tema a ser abordado por muito tempo no processo de formação inicial e continuada do professor alfabetizador. Ressaltamos que essa evidência tem tomado novas formas nesse contexto de pandemia que estamos vivendo nos últimos meses.

Dado o exposto, demanda-se à formação continuada realizar ações pertinentes que não traduzam apenas as TD como um recurso educacional e pedagógico, mas que promovam o incentivo à melhoria das práticas pedagógicas dos professores alfabetizadores. Resume-se, portanto, que a relação do professor alfabetizador para os usos das TD em sala de aula decorre, legitimamente, dos saberes docentes construídos e desenvolvidos em sua prática.

\section{As tecnologias digitais e a aprendizagem da língua escrita}

Discutir sobre a alfabetização e como alfabetizar os alunos no cenário brasileiro consiste, historicamente, em uma ação conflituosa (MORTATTI, 2006), no sentido de se pensar em quais métodos abordar para que os alunos efetivamente se alfabetizem, em outras palavras, aprendam a língua escrita na escola. As práticas pedagógicas dos professores alfabetizadores, ao longo do século XX, voltavam-se cada vez mais para o ensino da leitura e da escrita em textos impressos (ROJO, 2013). Todavia, em vista dos estudos mais recentes (ROJO, 2012, 2013), apontam-se que a variedade de textos apresentados aos alunos transcende aos textos comumente impressos para as produções linguísticas digitais. Realçando, a ênfase cada vez maior aos usos dos gêneros digitais apresentados pela esfera virtual (ROJO, 2013).

A relação entre os usos das TD e o ensino da língua escrita, segundo Teberosky e Colomer (2003), inicia-se desde a aquisição de uma técnica. Essa técnica envolve aprender a usar as teclas do teclado do computador, com isso, os alunos em processo de alfabetização,

Aprendem a conhecer o teclado da máquina - no teclado estão as letras do
alfabeto, além de outros signos. A materialização no teclado ajuda-as a
representar o conjunto finito de letras com as quais se trabalha e, além disso,
ajuda-as a estabelecer relações tipográficas. (TEBEROSKY; COLOMER,
2003, p. 31).

As relações entre o processo de alfabetização e os usos das TD permitem ao aluno compreender além da relação entre o som e a grafia os saberes sobre as multimodalidades (ROJO, 2013) necessários à leitura de textos na tela. Com base nesse entendimento, desenvolvem-se mecanismos que incorporam os múltiplos letramentos (ROJO, 2013). Dudeney, Hockly e Pegrum 
(2016, p. 63), ao discorrerem sobre a integração do uso das TD na sala de aula, afirmam que os professores "devem almejar atingir um ponto no qual seu conhecimento de conteúdo e pedagógico tradicional seja intensificado pelo conhecimento tecnológico". Com isso, o conhecimento tecnológico, necessário para o efetivo uso das TD, trata-se de uma especialização adicional, um complemento à práxis, ou seja, não substitui ou anula o conhecimento e a base de competências (DUDENEY; HOCKLY; PEGRUM, 2016).

No que se refere também aos usos das TD durante o processo de aquisição da língua escrita, Agranito, Teixeira e Santos (2013) afirmam que a inserção desses recursos às práticas pedagógicas influencia diretamente na alfabetização e nas práticas de letramento dos alunos. Desse modo, os alunos podem se sentir mais engajados e curiosos durante as atividades com os usos das TD em sala de aula. De acordo com Zacharias (2016, p. 20), a "expansão das tecnologias da informação e comunicação vem transformando a vida em sociedade e alterando a nossa relação com os textos". Sendo assim, professores e alunos em processo de alfabetização podem utilizar de uma diversidade de plataformas e textos que produzem sentidos por meio dos recursos multimodais em situações de aquisição da linguagem, a multimodalidade. Oliveira e Dias (2016, p. 82) apresentam a multimodalidade como "a recente diversidade de recursos semióticos para compor textos impressos ou digitais", que por sua vez, se insere nas interações pela linguagem oral ou escrita".

Binotto e Sá (2014) defendem que a utilização do laboratório de informática e do desenvolvimento de atividades voltadas aos usos das TD contribuiu significativamente para a aprendizagem dos alunos no processo de alfabetização. Vale ressaltar a importância das TD para a aquisição da língua escrita e a sua relação com o planejamento pedagógico. Nessa direção, Bianchini e Fruet (2019) afirmam que

[...] as TIC são recursos riquíssimos para a alfabetização e letramento, quando explorados conjuntamente com um bom planejamento pedagógico que os adapte aos níveis de alfabetização dos alunos. [...] Percebeu-se ainda que, além das habilidades de leitura e escrita, os alunos puderam desenvolver a autonomia, a autoestima e a sensação de segurança, características importantes para um processo ensino-aprendizagem bem sucedido. (BIANCHINI; FRUET, 2019, p. 15-16).

É necessário compreender os usos das TD no processo de alfabetização tendo em vista a elaboração de objetivos de aprendizagem pertinentes para o momento em que os alunos se encontram, definindo critérios e atividades relevantes em suportes também virtuais. A partir disso, entende-se a relevância das TD no contexto educacional em meio a sua relação com a 
aprendizagem nos processos de alfabetização de modo que desenvolvam a autonomia do aluno para ler e escrever em diferentes suportes impressos e virtuais.

$\mathrm{Na}$ continuidade do artigo, procede-se a análise do corpus da pesquisa no intuito de dialogar com a percepção dos professores alfabetizadores acerca dos usos das TD no ambiente escolar. Os colaboradores, como mencionado, responderam um questionário on-line sobre os usos do celular na sala de aula e as tecnologias no processo de alfabetização dos alunos.

\section{Desdobramentos: leituras possíveis dos dados}

Nessa investigação, as vozes dos professores alfabetizadores tematizaram os seus entendimentos sobre os usos das tecnologias digitais, cujo interesse de pesquisa consistia em analisar as categorias: I) concepções dos professores sobre tecnologias digitais; II) usos das tecnologias na sala de aula; III) formação continuada para o uso das tecnologias; IV) uso do celular em sala de aula; V) usos das tecnologias no processo de alfabetização.

\section{Concepções dos professores sobre tecnologias digitais}

As reverberações dos professores sobre as TD não se distanciam das concepções de Pinto (2008), apresentadas anteriormente, entendendo que não existe apenas um conceito para o termo, mas todas as quatro acepções se referem às nuances que envolvem a tecnologia (a tecnologia como o logos da técnica; a tecnologia como a própria técnica; a tecnologia como um conjunto de técnicas de uma sociedade no tempo; a tecnologia como ideologização da técnica). Na Tabela 1, apresentamos as definições dos professores sobre o significado de TD:

Tabela 1: Definições polissêmicas de tecnologias digitais

\begin{tabular}{l|c}
\hline 1. Internet, celular, computador e tablet & 28 \\
2. Aparelhos eletrônicos & 2 \\
3. Ferramenta para o ensino e aprendizagem & 6 \\
4. Meios de comunicação & 5 \\
5. Aglomerados de recursos produzidos pelo homem & 1 \\
6. Métodos tecnológicos em sala de aula & 1 \\
7. Recursos metodológicos & 7 \\
8. Artefatos tecnológicos & 13 \\
9. Não opinaram & 3 \\
\hline
\end{tabular}

Fonte: Dados da pesquisa, 2020. 
Das 66 (sessenta e seis) participações dos professores alfabetizadores as 9 (nove) respostas, categorizadas na Tabela 1, sintetizam as compreensões dos professores da rede pública de Maceió sobre TD. Entre as referidas respostas, é sintomático perceber que a definição de tecnologia como um método ou metodologia é atribuído por 8 (oito) deles. Se o método pode ser entendido como "um conjunto de procedimentos que, fundamentados em teorias e princípios, orientem a aprendizagem (...)" (SOARES, 2016, p. 330), ao compreender as tecnologias digitais como um método, os professores consideram sua relação com a aprendizagem, mas demonstram desconhecimento do entendimento das TD como instrumento para se chegar à aprendizagem. É possível a esse ponto, dialogar com o pensamento de Santos e Cavalcante (2019) sobre a necessidade premente de que a escola tem de estar atenta e aberta às mudanças que a inserção da sociedade no mundo digital exige para socialização de novas gerações. Outrossim, ao fazer a relação tecnologia-aprendizagem exige-se conhecimento técnico e prático por parte dos professores e da comunidade escolar sobre como mediar às aprendizagens.

Na Tabela 1, observa-se ainda que das definições sobre TD, foram mais recorrentes entre os professores alfabetizadores as indicações: "internet, celular, computador, e tablet, informadas por 28 participantes", e "artefatos tecnológicos" sinalizada por um participante. Essas respostas implicam no entendimento de que os professores não têm um conceito de TD, mas as associam aos meios ou recursos tecnológicos. Entretanto, quando os professores se referem ao termo “artefatos tecnológicos", existe implicitamente uma compreensão de que as TD não se restringem apenas aos artefatos tecnológicos, mas estão relacionadas à cultura (PINTO, 2008).

Rojo (2012), ao discutir os multiletramentos na escola, deixa claro que os artefatos tecnológicos fazem parte da sociedade contemporânea, permeada pelas tecnologias e pelas multilinguagens. Nesse ponto, as TD são consideradas artefatos no sentido de sua incompletude tendo em vista que as tecnologias digitais não solucionam todos os problemas, mas são necessários outros elementos que contribuem no processo educativo mediante as experiências de aprendizagem promovidas pelo professor aos alunos. $\mathrm{O}$ entendimento dos professores alfabetizadores de que as TD são um "meio de comunicação" fazem menção à relação do homem como um ser dialógico, que ao interagir com o outro se constitui por meio da linguagem (BAKHTIN, 2019).

\section{Usos das tecnologias na sala de aula}

Em se tratando da relação entre os usos das TD no processo de alfabetização enquanto uma possibilidade de propor "novas" interações dialógicas (BAKHTIN, 2003) e de ampliar a 
competência linguística dos alunos referente ao domínio da língua escrita, os professores alfabetizadores foram questionados sobre como acontece a inserção das tecnologias no seu planejamento pedagógico. As respostas foram sistematizadas no Gráfico 1:

Gráfico 1:Usos das tecnologias digitais

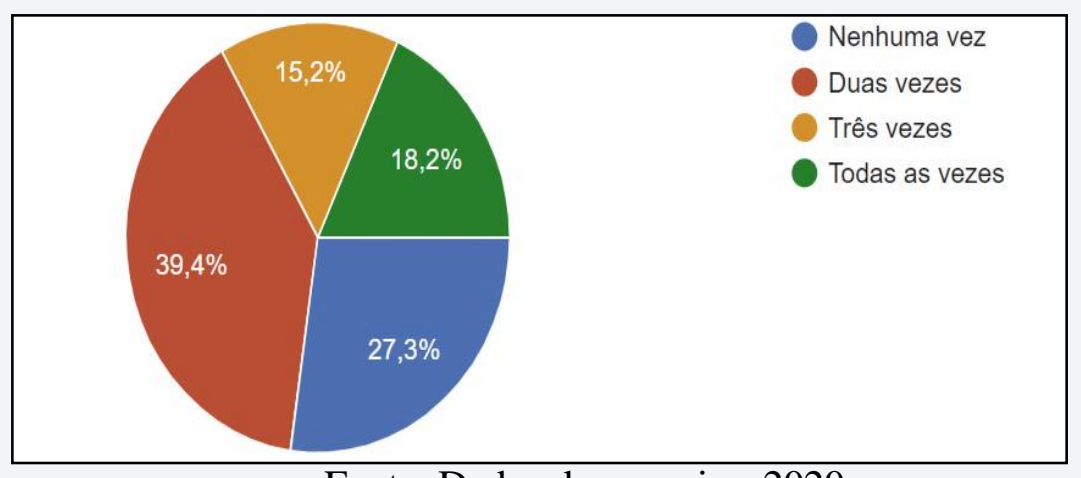

Fonte: Dados da pesquisa, 2020.

O Gráfico 1 revela a necessidade de outras investigações relacionadas ao planejamento dos professores e os usos das TD, tendo em vista que, 39,4\% dos participantes afirmaram que ao elaborarem seus planejamentos, inserem as tecnologias em suas aulas duas vezes por semana, enquanto que 18,2\% informam inserir "todas as vezes", e 15,2 \% afirmaram inserir três vezes. Esses percentuais são significativos, considerando a indicação do uso das TD em escolas públicas. Despertam, assim, a curiosidade em saber como, quando e em quais contextos essas TD são utilizadas em prol das aprendizagens em contextos de alfabetização.

Os dados apresentados no Gráfico 1 provocam reflexões considerando que 27,3\% afirmam não inserir "nenhuma vez" as TD em seus planejamentos. Esses dados, suscitam novas provocações: quais são os fatores que levam os professores a não usarem as tecnologias digitais em nenhum momento na sala de aula? Em contraponto, quais são os fatores que possibilitam os professores a usarem as tecnologias digitais todos os dias? Tendo em vista que os alunos, em sua grande maioria, utilizam diariamente artefatos tecnológicos (ROJO, 2016).

\section{Formação continuada para o uso das tecnologias}

As discussões sobre a formação do professor alfabetizador (SANTOS et al, 2018; SANTOS; SANTOS; SANTOS, 2020) apontam que muitos professores das escolas públicas não estão preparados para fazer uso das tecnologias na sala de aula nas práticas de alfabetização e não sabem como utilizá-las como ferramentas em suas práticas pedagógicas, além de outros aspectos, não dispõem de acesso aos referidos recursos e nem à rede de internet nas escolas. Por isso, quando se discorre sobre a importância dos processos de formação do professor alfabetizador, 
preza-se principalmente sobre melhores condições de trabalho e aos processos de qualificação profissional, pois, o professor em pleno exercício da profissão reflete sobre as suas vivências em sala de aula. Sobre as propostas de formação do professor alfabetizador observem o Gráfico 2:

Gráfico 2: Formação continuada para os usos de tecnologias digitais

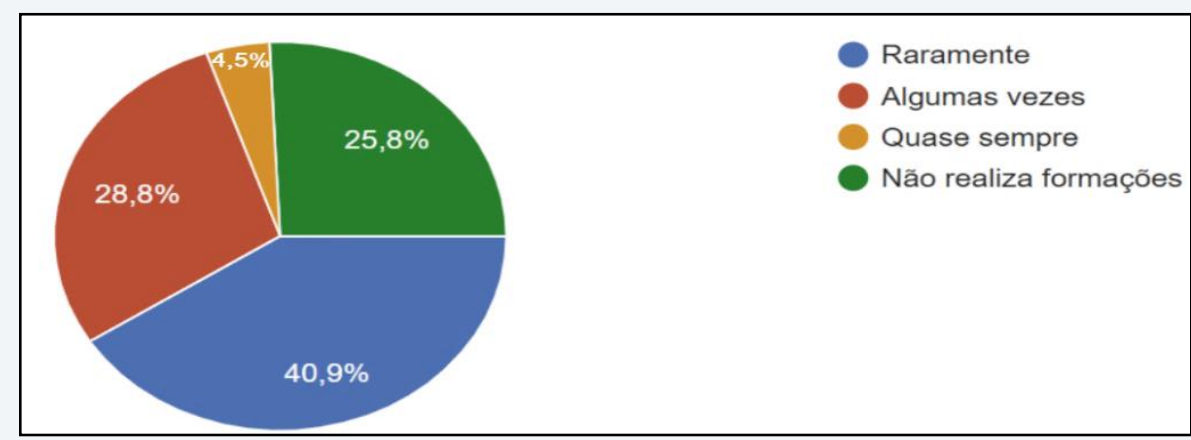

Fonte: Dados da pesquisa, 2020.

O Gráfico 2 demonstra que cerca de 40,9\% dos professores apontam que "raramente" acontecem formações continuadas que discutem os usos das TD na sala de aula. Como afirma Almeida (2000, p. 47) "não se trata de uma formação apenas na dimensão pedagógica nem de uma acumulação de teorias e técnicas", em outras palavras "uma formação que articula a prática, a reflexão, a investigação e os conhecimentos teóricos requeridos para promover uma transformação na ação pedagógica", principalmente no que tange aos aspectos que envolvem a prática pedagógica e a sua relação com as TD.

Dos participantes, $25,8 \%$ dizem que nenhuma formação continuada é realizada e reforçam a falta de saberes docentes sobre a temática abordada. Essa realidade suscita questões extremamente difíceis sobre a maneira como os professores vão inserir as TD em suas práticas pedagógicas tendo em vista as exigências das "novas" orientações curriculares, a exemplo da Base Nacional Comum Curricular (BRASIL, 2017) e no cenário atual com as imposições de aulas remotas.

\section{Uso do celular em sala de aula}

Os usos dos dispositivos móveis como os smartphones e tablets em sala de aula com finalidade pedagógica passa a ser uma possibilidade num cenário em que, nem todas as escolas públicas no Brasil dispõem de laboratórios de informática. Corroborando na discussão, Dudeney, Hockly e Pegrum (2016) defendem a utilização dos aparelhos móveis como parte do processo de letramento da sociedade moderna, o "letramento móvel”. Na concepção dos autores, 


\begin{abstract}
Alguns dos novos e mais significativos desenvolvimentos em letramentos vêm sendo impulsionados pela emergência da internet móvel, apoiados na tecnologia sem fio e em dispositivos móveis como os smartphones[...] e os tablets (DUDENEY; HOCKLY; PEGRUM, 2016, p. 31).
\end{abstract}

Os investimentos que favorecem os letramentos na escola vão além dos usos dos dispositivos móveis, por isso, é oportuno pesquisar sobre os usos de tais aparatos tecnológicos por parte dos professores, bem como, conhecer o modo que os utilizam em suas aulas. No Gráfico 3 é possível observar a frequência do uso do celular em sala:

Gráfico 3: Usos do celular em sala de aula

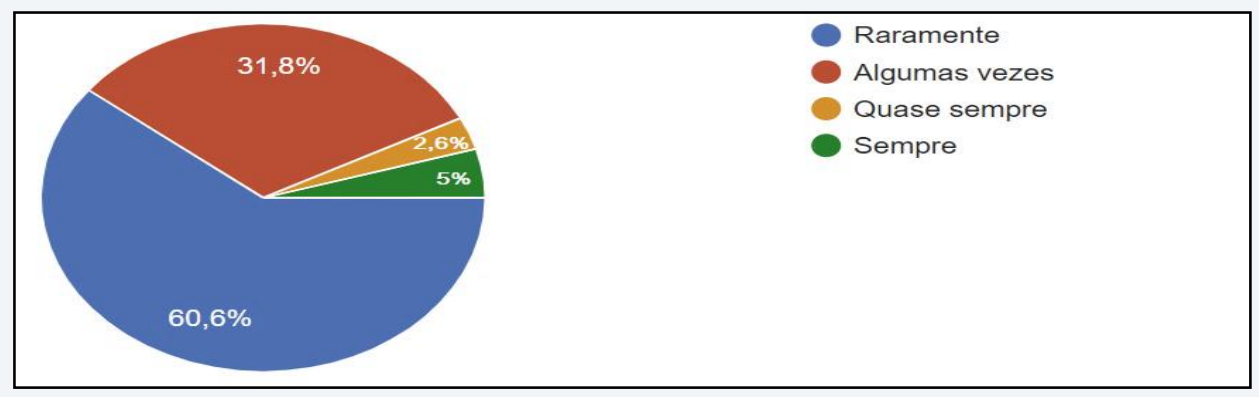

Fonte: Dados da pesquisa, 2020.

O Gráfico 3 evidencia que os professores não atribuem importância ao uso do celular como recurso pedagógico para suas aulas, visibilizando o que expõe Dudeney, Hockly e Pegrum (2016) sobre o usos de tais dispositivos e o letramento móvel próprios da cultura dos estudantes da atualidade, tendo em vista que 60,6\% dos professores raramente encorajam seus alunos a fazerem uso dos celulares em sala de aula. Thomas e O'Bannon (2014) afirmam que pelo fato de os dispositivos móveis serem naturalmente ubíquos, isto é, ter acesso em todo e qualquer lugar faz com que eles possam ser utilizados como recurso para o processo de ensino e aprendizagem fora da escola ampliando a relação entre o ensino e a aprendizagem.

É importante considerar que 31,8\% dos professores usam algumas vezes o celular como recurso pedagógico na sala de aula, pois, esse percentual reflete também acerca do acesso aos dispositivos móveis pelos alunos, considerando que parte dos alunos da rede pública de Maceió nem sempre têm celular ou podem levar para a escola.

O Gráfico 3 explicita que os professores não compreendem a importância dos usos das TD no sentido de influenciar diretamente e positivamente durante o processo de alfabetização dos alunos, de modo pelo qual, ambos (alunos e professores), percebam que além dos gêneros impressos, existem os gêneros digitais, e com isso, os domínios da leitura e produção de diferentes 
gêneros e em diferentes suportes no processo de alfabetização implicam na construção de múltiplos letramentos (ROJO, 2013).

Os múltiplos letramentos, por sua vez, equivalem a uma multiplicidade de linguagens, a partir de uma vasta diversidade cultural, de forma que atrelado aos usos sociais da língua escrita podem contribuir nas práticas sociais dos sujeitos (SOARES, 2003). Nesse sentido, a que se garantir que os alunos estejam imersos em um cenário de múltiplas linguagens.

\section{Usos das tecnologias no processo de alfabetização}

Os dados a seguir nos apresentam a percepção que têm os professores quanto à contribuição dos usos das tecnologias digitais no processo de alfabetização de crianças. Segundo Pimentel e Costa (2017, p. 165), "há crianças que nasceram nesta era digital, mas que ainda não estão inseridas neste contexto por questões econômicas, implicando numa limitação de acesso as TD inclusive nas escolas". Para os autores, as crianças podem ser reconhecidas como excluídas digitalmente, mesmo tendo nascido num contexto de cultura digital. A concepção dos professores, sobre os usos de tecnologia digitais na alfabetização, pode ser observada no Gráfico 4.

Gráfico 4: Uso das tecnologias digitais no processo de alfabetização

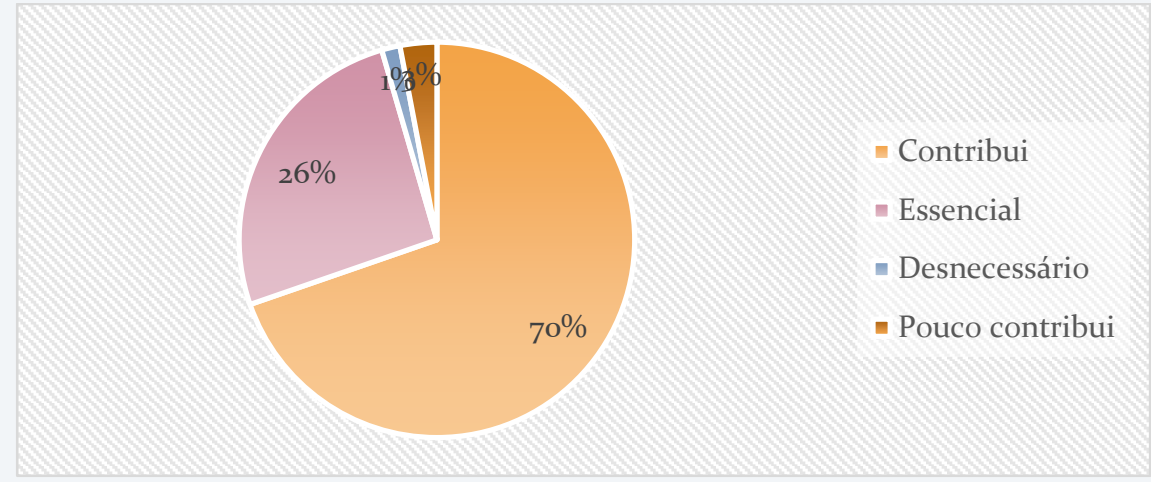

Fonte: Dados da pesquisa, 2020.

Em se tratando da importância das TD para o processo de alfabetização, há uma relação diferente com os Gráficos 1 e 3, tendo em vista que 69,7\% dos professores afirmaram que as TD contribuem para o processo de aquisição da língua escrita. Mas ao se observar os Gráficos (1 e $3)$, os professores raramente $(60,6 \%)$ fazem uso das TD em seus planejamentos e não encorajam nenhuma vez $(27,3 \%)$ seus alunos a fazerem uso de dispositivos móveis na sala de aula.

É pertinente enfatizar o reconhecimento por parte dos professores da contribuição das TD no processo de alfabetização dos alunos, informando que 25,8\% deles também acreditam que as 
TD não só contribuem, mas também são essenciais para a aquisição da língua escrita. Essa evidência, remete à problemática de aumentar a frequência da presença das TD no planejamento e de incentivar o uso do celular na sala de aula. Dessa forma, é possível fazer com que professores e alunos participem na construção desses saberes.

A investigação vai mostrando que os professores alfabetizadores acreditam que as TD são fundamentais para os processos de ensino e aprendizagem e que elas contribuem para o avanço dos alunos na aquisição da língua escrita. O gráfico a seguir expõe os recursos digitais informados por no mínimo 5 (recorrências). O Gráfico 5 sistematiza as respostas dos professores alfabetizadores:

Gráfico 5:Recursos tecnológicos considerados fundamentais

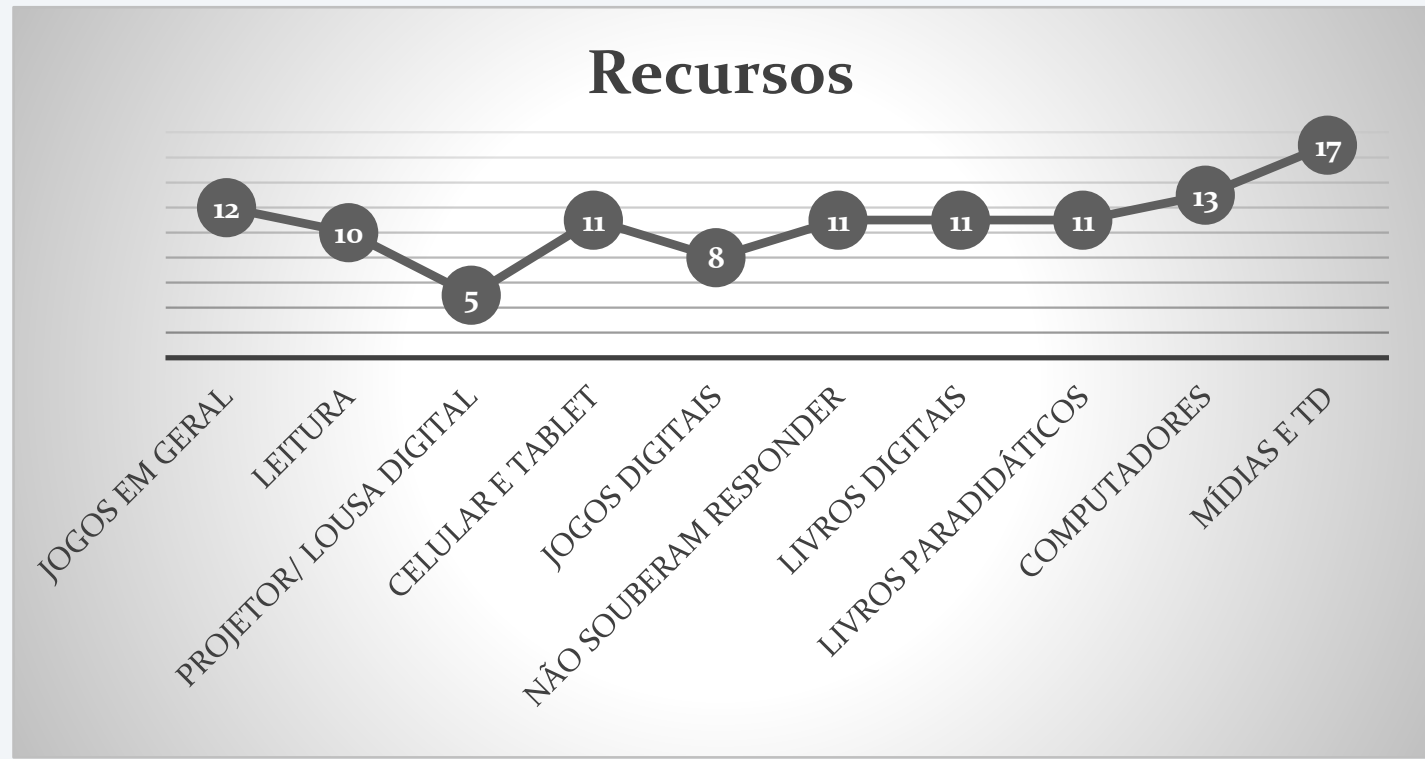

Fonte: Dados da pesquisa, 2020.

O Gráfico 5 demonstra que a maioria dos professores consideram a utilização de mídias e TD como recursos fundamentais para o avanço dos alunos na aquisição da língua escrita, dentre as mídias e TD citadas destacam-se: vídeos, apresentação eletrônica e músicas. Nesse sentido, Rojo (2012,p. 23) destaca que as mídias digitais e os multiletramentos como recursos “a) [...] são interativos; mais que isso, colaborativos; [...] c) [...] são híbridos, fronteiriços, mestiços". Os professores alfabetizadores partícipes da investigação podem estar construindo a concepção de que o uso das mídias e TD, por todo seu potencial múltiplo, é significativo para a aquisição da língua escrita. 
Os professores alfabetizadores chamam atenção (ver Gráfico 5) sobre a importância do uso de computadores e notebooks (13), os laboratórios de informática da escola. Destacaram também o uso do celular (11) com uma recorrência importante na resposta dos professores, a utilização dos jogos não digitais e digitais (somam 20 recorrências) como recurso significativo na aprendizagem da língua escrita.

Entre os professores alfabetizadores, ao serem interrogados sobre quais recursos consideravam fundamentais para contribuir no avanço dos alunos na aquisição da língua escrita, o professor P1 reverberou:

Vivemos numa sociedade complexa com múltiplas linguagens e culturas, nas
quais, fenômenos como memes, remix e mensagens instantâneas se fazem
presentes e marcadas atualmente pela convergência da mídia, a partir disso, a
escola tem o desafio de letrar (os alunos) não apenas para os gêneros textuais
impressos, mas para um gama de textos que circulam na cultura digital [...]. Para
o desenvolvimento da alfabetização e letramentos temos aplicativos com Editor
e HQs, que permitem desenvolver histórias em quadrinhos em formato digital,
bem como, aplicativos de dicionários que trazem as palavras em ordem
alfabética e com seus significados, temos por exemplo, o MyStory Book
CreatorSchoolEdition que possibilita a criação autoral de histórias dentre outros
recursos digitais que serão utilizados conforme os objetivos de aprendizagem e
planejamento pedagógico.

Percebemos que P1 possui uma percepção significativa quanto aos usos das tecnologias digitais, sobretudo, as contribuições destas para a aquisição da língua escrita, ao destacar os desafios impostos pelo contexto de cultura digital, que exigem novos letramentos. Bem como, exemplifica ao fazer menção as histórias em quadrinhos (HQs) e a produção autoral.

Outro fator que nos chamou atenção no Gráfico 5 relaciona-se à quantidade de professores (11) que não souberam responder ao questionamento e optaram por produzir respostas vagas, como podemos observar na afirmação: "todos os recursos que estejam ao alcance" (P2). Percebemos, no depoimento de $\mathrm{P} 2$, que quando preenchia o questionário, não soube responder ao questionamento e informar quais recursos acreditava ser fundamental para contribuir no avanço dos alunos. O colaborador P2 não conseguiu realizar a distinção de quais recursos são fundamentais e ou contribuem para o avanço da aquisição da língua escrita. Essa dificuldade de entendimento sobre os questionamentos pode ser observada nas respostas de 11 professores alfabetizadores.

A análise dos questionários revelou que não basta apenas reconhecer a importância dos usos da TD nos processos de alfabetização, mas o professor também precisa saber fazer usos de tais tecnologias. Dudeney, Hockly e Pegrum (2016, p. 305) abordam o domínio das competências tecnológicas necessárias aos professores para o uso das tecnologias digitais, tais como: escrever 
hipertextos, criar um infográfico, criar um vodcast, um cartaz multimídia, escrever uma postagem num blog ou criar um remix, dentre outros. Segundo os autores, sem esse conhecimento, há dificuldade por parte dos professores em interagir com as mídias digitais, próprias da cultura digital.

\section{Considerações finais}

A pesquisa mostra que os professores alfabetizadores apresentam dificuldades relacionadas ao entendimento do conceito de TD. E, compreendem as TD como metodologia de ensino ou um suporte tecnológico a qual não se relaciona diretamente com o processo de ensino e aprendizagem. Os dados reverberam que alguns colaboradores associam o conceito das TD como artefato tecnológico. Esse entendimento reflete uma relação proximal das TD com a sociedade, percebendo nas entrelinhas que os artefatos tecnológicos se transformam conforme as mudanças da sociedade (PINTO, 2008), reconhecendo-os assim o aspecto cultural.

Com relação aos usos das tecnologias na sala de aula ficou evidente que os professores alfabetizadores costumam usá-las no mínimo duas vezes por semana em seu planejamento. Contudo, a quantidade de professores que não usam nenhuma vez as TD também apresentou um dado significativo, revelando que os usos das TD na a sala de aula e a prática pedagógica do professor é uma realidade distante das escolas públicas. Essa relação precisa ser discutida nas formações continuadas e nos encontros pedagógicas nos loci das escolas, porém, com mais ênfase pós-pandemia do novo coronavírus.

Em se tratando da formação continuada para o uso das tecnologias, os sujeitos da investigação informaram que existe uma necessidade emergente de ter formações continuadas que discorram sobre essa temática, principalmente para os professores que estão envolvidos com o processo de aquisição da língua escrita de seus alunos (BIANCHINI; FRUET, 2019). É imprescindível pontuar o quanto as TD contribuem para a aprendizagem da língua escrita, de modo que através da interatividade entre aluno e máquina seja possível observar as múltiplas linguagens que emergem dos gêneros digitais.

Sobre os usos do celular em sala de aula enquanto uma interface que pode proporcionar aprendizagens, os dados apontaram que o incentivo para o seu uso acontece raramente por parte dos professores. Os dados indicam que os sujeitos da investigação possuem dificuldade para planejar suas aulas tendo o dispositivo móvel como suporte pedagógico para os recursos digitais educacionais, assim, acabam usando materiais em sua maioria impressos do que os relacionados 
às $\mathrm{TD}$, os quais proporcionariam maior uso e aproximação de diferentes gêneros discursivos e, principalmente, os de cunho digital.

A investigação indica que os usos das tecnologias no processo de alfabetização contribuem de forma significativa para a aprendizagem dos alunos. É legítimo reconhecer que os professores concordaram em sua maioria $(69,7 \%)$ que as TD favorecem o processo de aquisição da língua escrita e alguns ainda apontaram que essa relação seria essencial para que os alunos aprendessem a ler e escrever efetivamente. Com isso, torna-se possível perceber que as TD favorecem diretamente o ensino e aprendizagem nos processos de alfabetização, além de que o aluno pode participar de maneira mais dinâmica e ativa das vivências em sala de aula.

\section{REFERÊNCIAS}

AGRANITO, Laís de Castro; TEIXEIRA, Priscila Gervásio; SANTOS, Eliane Elias Ferreira dos. A Utilização das Tecnologias Digitais no Processo de Alfabetização e Letramento na Escola de Educação Básica da Universidade Federal de Uberlândia - ESEBA/UFU. Revista de Educação e Ensino Olhares e Trilhas. Ano XIV. Números 17 e 18. JAN./DEZ. 2013.

ALMEIDA, Maria Elizabeth Bianconcini de. Informática e formação de professores. ProInfo. v. 2. Secretaria de Educação a Distância. Brasília: Ministério da Educação, Seed, 2000.

BACICH, Lilian; TANZI NETO, Adolfo; TRIVISANI, Fernando de Mello. Ensino Híbrido: personalização e tecnologia na educação. In: BACICH, Lilian; TANZI NETO, Adolfo; TREVISANI, Fernando de Mello. Ensino híbrido: personalização e tecnologia na educação. Porto Alegre: Penso, 2015.

BAKHTIN, Mikhail. Estética da criação verbal. 4. ed. São Paulo: Martins Fontes, 2003.

BAKHTIN, Mikhail. O homem ao espelho: apontamentos dos anos 1940. São Carlos: Pedro e João Editores, 2019.

BIANCHINI, Rejane; FRUET, Fabiane Sarmento Oliveira. Integração das Tecnologias nos Processos de Alfabetização e Letramento: Investigação-ação educacional em uma escola pública da rede municipal de Lajeado - RS, 2019. Disponível em:

<https://www.ufsm.br/unidades-universitarias/ce/wp-content/uploads/sites/373/2019/06/RejaneBianchini-e-Fabiane-Sarmento-Oliveira-Fruet.pdf> Acesso em: 17 abr. 2020.

BINOTTO, Claudia; SÁ, Ricardo Antunes de. Tecnologias digitais no processo de alfabetização: analisando o uso do laboratório de informática nos anos iniciais. Práxis Educacional, Vitória da Conquista, v. 10, n. 17, p. 315-332, jul./dez., 2014.

BRASIL. Ministério da Educação. Secretaria da Educação Básica. Base Nacional Comum Curricular. Brasília, DF, 2017. Disponível em:<http://basenacionalcomum.mec.gov.br/wpcontent/uploads/2018/02/bncc-20dez-site.pdf.> Acesso em: 01 jun. 2018. 
CERNY, Roseli Zen; ESPÍNDOLA, Marina Bazzo de; TOSATTI, Nayara Cristine Müller. A Relação entre Educação e Tecnologias Digitais de Informação e Comunicação: percepções de cursistas da formação continuada. Revista Tecnologias na Educação, Ano 10, Número/Vol.25, jul., 2018.

CERTEAU, Michel: A invenção do cotidiano: 1. Artes de fazer. Petrópolis: Vozes, 2008.

CHARTIER, Anne-Marie. Fazeres ordinários da classe: uma aposta para a pesquisa e para a formação. Educação e Pesquisa. São Paulo, v. 26, n.2, 2000.

COLOMER, Teresa; CAMPS, Anna. Ensinar a ler, ensinar a compreender. Porto Alegre: Artmed, 2002.

DUDENEY, Gavin; HOCKLY, Nicky; PEGRUM, Mark. Letramentos digitais. Tradução de Marcos Marcionilo. São Paulo: Parábola Editorial, 2016.

FREIRE, Paulo. Pedagogia do Oprimido. 17. ed. Rio de Janeiro: Paz e Terra, 1987.

FULLAN, Michael; HARGREAVES, Andy. Porque é que vale a pena lutar? O trabalho de equipe na escola. Porto: Porto Editora, 2001.

HARGREAVES, Andy. Os professores em tempos de mudança: o trabalho e a cultura dos professores na Idade Pós-Moderna. Lisboa: McGraw-Hill, 2001.

MARTINS, Onilza Borges; MASCHIO, Elaine Cátia Falcade. As Tecnologias Digitais na Escola e a Formação Docente: representações, apropriações e práticas. 2014. Disponível em: <https://www.scielo.sa.cr/pdf/aie/v14n3/a20v14n3.pdf> Acesso em: 16 abr. 2020.

BRASIL. Ministério da Educação. ProInfo, 2007. Disponível em: <http://portal.mec.gov.br/proinfo> Acesso em: 16 abr. 2020.

MORTATTI, Maria Rosário Longo. História dos Métodos de Alfabetização no Brasil. Ministério da Educação (MEC), 2006. Disponível em:

$<$ http://portal.mec.gov.br/seb/arquivos/pdf/Ensfund/alf_mortattihisttextalfbbr.pdf > Acesso em: 27 mar. 2020.

NUNES, Célia Maria Fernandes. Saberes Docentes e Formação de Professores: um breve panorama da pesquisa brasileira. Educação \& Sociedade, ano XXII, nº 74, Abril/2001. Disponível em: < http://www.scielo.br/pdf/es/v22n74/a03v2274.pdf> Acesso em: 17 abr. 2020.

OLIVEIRA, Tâmara LyzMilhomem de; DIAS, Reinildes. Multimodalidade ontem e hoje nas homepages do yahoo:trilhando uma análise diacrônica de textos multimodais. In: KERSCH, Dorotea Frank; COSCARELLI, Carla Viana; CANI, Josiane Brunetti(org.).Multiletramentos e multimodalidade: ações pedagógicas aplicadas à linguagem. Campinas: Pontes Editores, 2016.

PIMENTEL, Fernando Silvio Cavalcante; COSTA, Cleide Jane de Sá Araújo. A cultura digital no cotidiano das crianças: apropriação, reflexos e descompassos na educação 
formal.In: COSTA, Cleide Jane de Sá Araújo; PINTO, Anamelia de Campos (org.). Tecnologias digitais da informação e comunicação na educação. Maceió: Edufal, 2017.

PINTO, Álvaro Vieira. O conceito de tecnologia. São Paulo: Contraponto, 2008.

RIBEIRO, Andréa Lourdes. Jogos online no ensino-aprendizagem da leitura e da escrita. In: COSCARELLI, Carla Viana (org.). Tecnologias para aprender. São Paulo: Parábola Editorial, 2016.

ROJO, Roxane. Pedagogia dos multiletramentos: diversidade cultural e de linguagens na escola. In:ROJO, Roxane; MOURA, Eduardo. Multiletramentos na escola. São Paulo: Parábola Editorial, 2012.

ROJO, Roxane. Escola Conectada: os multiletramentos e as TICs. São Paulo: Parábola, 2013.

SANTOS, Adriana Cavalcanti dos. O ensino da leitura na educação de jovens e adultos: o movimentum de significar e ressignificar a prática docente em contexto de pesquisa colaborativa. 2014. 278 f. Tese (Doutorado em Educação) - Centro de Educação, Programa de Pós-Graduação em Educação, Universidade Federal de Alagoas, Maceió, 2014.

SANTOS, Nádson Araújo dos; CAVALCANTE, Maria Auxiliadora da Silva. Gêneros textuais e tecnologias digitais na escola: diálogos possíveis. In: SANTOS; Adriana Cavalcanti dos; SANTOS, Nádson Araújo dos (orgs.).Educação e linguagem: interfaces de investigação em rede. Maceió: Edufal, 2019.

SANTOS, Adriana Cavalcanti dos; CAVALCANTE, Maria Auxiliadora da Silva; SILVA, Silvana Paulina da; FIREMAN, Elton Casado. Formação do professor-alfabetizador no movimentum de uma gestão curricular ativa. Espacios (Caracas), v. 39, p. 30-38, 2018.

SANTOS, Adriana Cavalcanti dos; LEITE, Carlinda. Políticas de currículo em Portugal: Concepções e práticas. Linhas Críticas (UNB), v. 25, p. 24-40, 2019.

SANTOS, Adriana Cavalcanti dos; SANTOS, Wilton Petrus dos; SANTOS, Nádson Araújo dos. A produção textual em contextos do letramento e significação social. Horizontes, [S.1.], v. 38, n. 1, p. e020006, fev. 2020. ISSN 2317-109X. Disponível em:

<https://revistahorizontes.usf.edu.br/horizontes/article/view/846/419>. Acesso em: 20 maio 2020. doi:https://doi.org/10.24933/horizontes.v38i1.846.

SILVA, Gildemarks Costa e. Tecnologia, educação e tecnocentrismo: as contribuições de Álvaro Vieira Pinto. Rev. bras. Estud. pedagog. (on-line), Brasília, v. 94, n. 238, p. 839-857, set./dez. 2013. Disponível em: <http://www.scielo.br/pdf/rbeped/v94n238/a10v94n238.pdf> Acesso em: 16 abr. 2020.

SOARES, Magda. A Reinvenção da Alfabetização. Revista Presença Pedagógica, Belo Horizonte, v.9, n.52, jul/ago, 2003. Disponível em:

<http://www.gestaoescolar.diaadia.pr.gov.br/arquivos/File/programa_aceleracao_estudos/reiven cao_alfabetizacao.pdf> Acesso em: 28 jan. 2020.

SOARES, Magda. Alfabetização: a questão dos métodos. São Paulo: Contexto, 2016. 
TARDIF, Maurice. Saberes docentes e formação profissional. 3. ed. Petrópolis: Vozes, 2003.

TEBEROSKY, Ana; COLOMER, Teresa. Aprender a ler e a escrever: uma proposta construtivista. Porto Alegre: Artmed, 2003.

THOMAS, Kevin; O’BANNON, Blanche. Cell Phones in the Classroom: preservice teacher's perceptions. Journal of Digital Learning in Teacher Education. Vol 30. Number 1. 2014.

TRIVIÑOS, Augusto Nibaldo Silva. Introdução à pesquisa em ciências sociais: a pesquisa qualitativa em Educação. São Paulo: Atlas, 2013.

VILELA, Heloísa de Oliveira Santos. O Mestre-Escola e a Professora. In: LOPES, Eliane Marta Teixeira; FARIA FILHO, Luciano Mendes; VEIGA, Cynthia Greive. 500 anos de Educação no Brasil. 4. ed. Belo Horizonte: Autêntica, 2010.

ZACHARIAS, Valéria Ribeiro de Castro. Letramento digital: desafios e possibilidades para o ensino. In: COSCARELLI, Carla Viana (org.). Tecnologias para aprender. São Paulo: Parábola Editorial, 2016.

\section{SOBRE OS AUTORES:}

\section{Adriana Cavalcanti dos Santos}

Pós-doutora em Ciências da Educação pela Universidade do Porto (Portugal). Doutora e Mestra em Educação pela Universidade Federal de Alagoas (UFAL); Professora Adjunta da Universidade Federal de Alagoas - Brasil; Grupo de Estudo e Pesquisa em Didáticas de Leitura, da Literatura e da Escrita (Gellite). Correio eletrônico: adricavalcanty@ hotmail.com

iD https://orcid.org/0000-0002-4556-282X

\section{Nádson Araújo dos Santos}

Doutorando e Mestre em Educação pela Universidade Federal de Alagoas (UFAL); Professor Bolsista do Instituto Federal de Alagoas - Brasil; Discente do Programa de Pós-Graduação em Educação (PPGE/UFAL); Grupo de Estudo e Pesquisa em Didáticas de Leitura, da Literatura e da Escrita (Gellite). E-mail: nadson.araujo@gmail.com

(iD https://orcid.org/0000-0003-2900-0322

\section{Viviane Caline de Souza Pinheiro}

Mestranda em Educação pela Universidade Federal de Alagoas (UFAL); Discente do Programa de Pós-Graduação em Educação (PPGE/UFAL); Grupo de Estudo e Pesquisa em Didáticas de Leitura, da Literatura e da Escrita (Gellite).

E-mail: viviane.cs.pinheiro@gmail.com

(iD https://orcid.org/0000-0001-9762-5418 